\title{
ANALISIS PERBANDINGAN PEMAKAIAN BAHAN WAJAN BOLIC DAN PROVIDER TELEKOMUNIKASI TERHADAP DAYA PENERIMAAN SINYAL DI DESA CIBUNTU
}

\author{
Halim Agung ${ }^{1}$, Lukman Hakim ${ }^{2}$ \\ ${ }^{1}$ Program Studi Teknik Informatika, Universitas Bunda Mulia Jakarta \\ hagung@bundamulia.ac.id \\ ${ }^{2}$ Program Studi Teknik Informatika, Universitas Bunda Mulia Jakarta \\ lhakim@bundamulia.ac.id
}

\begin{abstract}
ABSTRAK
Desa Wisata Cibuntu merupakan desa yang memiliki beberapa peninggalan benda bersejarah yang berada pada lereng gunung Cermai, Kecamatan pesawahan, Kabupaten Kuningan. Dinas Pariwisata dan Kebudayaan Jawa Barat menetapkan sebagai desa wisata yang dapat dijadikan destination utama. Minimnya teknologi komputerisasi yang digunakan serta minimnya area desa Cibuntu yang memiliki daya penerimaan sinyal yang kuat sehingga menyebabkan hampir seluruh wilayah desa mengalami blank spot sinyal dan membuat aktifitas administrasi desa yang berhubungan dengan pencarian informasi menggunakan internet terhambat maka analisa perbandingan dan pemakaian bahan wajan bolic dan provider telekomunikasi pada pembuatan wajan bolic menjadi solusi untuk memudahkan dalam penerimaan sinyal menggunakan wajan bolic pada desa wisata Cibuntu. Penelitian ini dilakukan bertujuan untuk menganalisis dan merancang suatu teknologi jaringan menggunakan alat-alat sederhana yang membantu dalam penerimaan sinyal dalam hal ini penggunaan bahan wajan bolic dan provider telekomunikasi yang sesuai dengan kondisi desa Cibuntu. Bahan wajan yang dibandingkan adalah aluminium murni dan aluminium campuran atau babet serta provider yang digunakan ada empat yaitu xl, three, simpati dan im3. Penelitian ini juga langsung dilakukan pada Desa Cibuntu sehingga hasil yang didapat lebih akurat. Hasil yang diperoleh dalam penelitian ini adalah penggunaan bahan aluminium murni dan provider simpati cocok digunakan pada kondisi desa Cibuntu dengan rata-rata ping time $<100 \mathrm{~ms}$.
\end{abstract}

Kata kunci: wajan bolic, provider telekomunikasi, desa cibuntu, aluminium, blank spot

\section{PENDAHULUAN}

Desa Cibuntu merupakan sebuah desa yang keberadaan desanya termasuk unik dikarenakan keberadaan desa tersebut merupakan ujung desa dan berada di lereng gunung ciremai, area desa setelah desa Cibuntu selanjutnya merupakan hutan pinus yang merupakan area hutan gunung ciremai. Desa Wisata (Hadiwijoyo, 2012) Cibuntu yang sudah terdaftar sebagai destinasi utama jawa barat yang banyak menyimpan potensi wisata alam serta budaya masyarakat disana, namun dalam perkembangan desa wisata tersebut masih terkendala dalam akses pada dunia maya dan kekuatan sinyal seluler sehingga sulit digunakan untuk berkomunikasi dalam hal ini berkomunikasi menggunakan internet. Teknologi komunikasi merupakan suatu keharusan untuk menjadi desa yang cerdas teknologi, Desa Cibuntu yang merupakan desa yang berada di lereng gunung Ceremai membuat terjadinya blank spot pada sinyal komunikasi seperti telepon dan internet sehingga menyebabkan hampir seluruh wilayah pada Desa Cibuntu tidak merasakan sinyal provider. Permasalahan diatas dapat diselesaikan dengan dibangunnya pemancar penguat sinyal seluler dan internet yaitu menggunakan wajan bolic yang dilengkapi repeater yang akan membuat daerah tersebut memiliki sinyal seluler dan akses internet dengan mudah. Wajan Bolic adalah sebuah antena nirkabel yang terbuat dari wajan yang telah dimodifikasi sehingga dapat digunakan untuk memperkuat sinyal radio atau sinyal internet, selain itu dengan biaya yang relatif murah yang dapat dibangun disetiap rumah (Muslim, 2008). 
Antenna Wajan, atau Wajanbolic e-goen merupakan terobosan dalam Teknologi RT/RW-net. Antenna Wajanbolic e-goen dapat menjadi client yang murah dalam sebuah RT/RW-net sehingga kita dapat ber Internet dengan murah. Internet murah bukan berarti mencuri bandwidth dan ber Internet gratis, seperti kebanyakan orang menyangka. Internet menjadi murah karena beban biaya di tanggung ramai-ramai oleh banyak mengguna di sebuah RT/RW dalam RT/RWnet (Wikipedia, 2012)

Dalam membuat wajan bolic diperlukan perhitungan yang akurat yang membuat wajan bolic dapat menangkap sinyal dengan baik. Berikut perhitungan ukuran wajan bolic sesuai dengan gambar 1 (Rahman, 2011; Adiyanto, 2008).

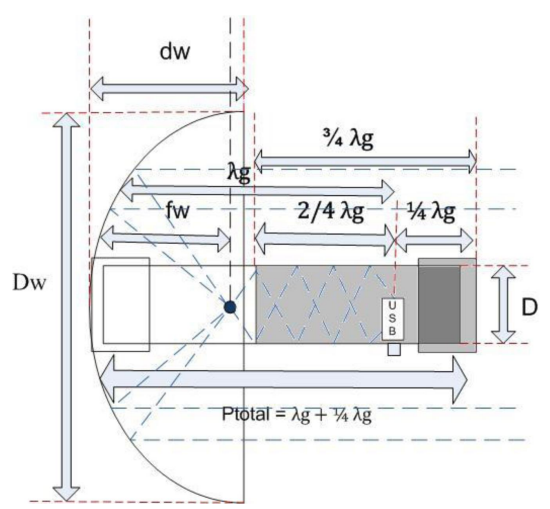

Gambar 1 Parameter Wajanbolic

Gambar 1 di atas merupakan gambar dengan parameter untuk desain pengukuran wajanbolic. Berdasarkan Gambar 1, pada perancangan wajanbolic dibutuhkan parameter :

$$
f w=\frac{D w^{2}}{16 * d w}
$$

Dengan $\mathrm{Dw}=$ Diameter Wajan, $\mathrm{dw}=$ kedalaman wajan dan $\mathrm{fw}=$ panjang lapisan yang tidak diberi aluminium foil.

$$
\lambda=\frac{C}{\text { Freq }}
$$

Dengan $\mathrm{C}=$ kecepatan cahaya di udara $\left(3 \times 10^{8} \mathrm{~m} / \mathrm{s}\right)$, Freq $=$ frekuensi yang digunakan $(2.4$ $\mathrm{GHz}), \lambda=$ panjang gelombang radio diudara. Untuk ukuran diameter pipa paralon harus memenuhi syarat dengan persamaan $0.6 \lambda<\mathrm{D}<0.75 \lambda$.

$$
\lambda_{0}=\frac{2 \times \pi \times r}{1.814}
$$

Dengan $\lambda_{0}=$ panjang gelombang dari low cut frekuensi yang tergantung dari diameter silinder, $\mathrm{r}$ $=$ jari-jari pipa paralon.

$$
\lambda_{g}=\frac{\lambda}{1-\left(\frac{\lambda}{1.706 \times D}\right)^{2}}
$$

Dengan $\lambda_{\mathrm{g}}=$ panjang gelombang frekuensi $2.4 \mathrm{GHz}$ didalam pipa paralon. 


$$
S=\frac{\lambda_{g}}{4}
$$

Dengan $\mathrm{S}=$ posisi USB Wireless adapater

$$
L=\frac{3}{4} \lambda_{g}
$$

Dengan $\mathrm{L}=$ panjang pipa paralon yang dilapisi aluminium

Untuk mengukur panjang total pipa yang digunakan dapat menggunakan rumus dibawah ini.

Dengan $\mathrm{P}_{\text {tot }}=$ panjang total.

$$
P_{t o t}=L+\frac{1}{4} \lambda_{g}
$$

Nugraha Yurandi, Lucia Jambola, Arsyad R yang dalam penelitiannya (Yurandi et al, 2013) menghasilkan penelitian yang menyatakan bahwa berdasarkan rata-rata level sinyal percobaan tanpa reflector, dengan reflector solid, dan dengan reflector grid. Dapat dilihat bahwa pada kondisi indoor, level sinyal tertinggi pada saat memakai reflector wajan dengan nilai sebesar 40,94 dBm dan pada kondisi outdoor, level sinyal tertinggi pada saat memakai reflector wajan dengan nilai sebesar $-75,38 \mathrm{dBm}$. Nilai gain pada saat teori sebesar $17.18 \mathrm{dBi}$, sedangkan gain berdasarkan pengukuran diperoleh nilai gain sebesar $17,065 \mathrm{dBi}$, berbeda $0,115 \mathrm{dBi}$ dengan gain secara teori. Sedangkan gain berdasarkan pengukuran pada USB wireless adapter sebesar 1.35 $\mathrm{dBi}$. Dari segi pola radiasi, pola pada reflector grid tampak lebih melebar dikarenakan sinyal gelombang electromagnet masih bisa masuk lewat sudut pinggiran reflector yang berupa jaring dan berdasarkan jumlah access point yang di tangkap oleh radar, dapat dilihat jika tanpa menggunakan reflector diterima 11 access point sedangkan pada saat menggunakan reflector grid diterima 14 access point dan saat menggunakan reflector wajan diterima 16 access point. Pada saat hanya menggunakan USB wireless adapter, pola radiasinya melebar sedangkan pada saat menggunakan reflector pola radiasinya lebih terarah.

Bayu Nur Huda (Huda, 2014), dalam penelitian membuat dan mengimplementasikan antena kaleng lebih sederhana dan sinyal yang diperoleh cukup baik, sedangkan untuk biaya pembuatannya relatif lebih hemat, tapi untuk pemfokusan sinyal masih kurang sehingga stabillitas sinyal masih kurang dibandingkan wajan bolic.

Lukman Hakim dan Halim Agung, (Hakim et al, 2016) Pada penelitiannya, menerapkan bahan wajan bolic menggunakan bahan aluminium campuran atau babet sebagai bahan pembuatan wajan bolic dan diimplementasikan pada desa Cibuntu.

\section{METODE PENELITIAN}

Prototype paradigma dimulai dengan pengumpulan kebutuhan. Secara ideal prototype berfungsi sebagai sebuah mekanisme untuk mengidentifikasi kebutuhan perangkat lunak. Bila prototipe sedang bekerja atau dibangun, pengembang harus mempergunakan fragmen-fragmen yang ada atau mengaplikasikan alat-alat bantu (Yasin, 2012). 
Prototype merupakan salah satu metode pengembangan perangkat lunak yang banyak digunakan. Dengan metode prototyping ini pengembang dan pelanggan dapat saling berinteraksi selama proses pembuatan sistem. Prototyping, dimulai dengan pengumpulan kebutuhan pelanggan terhadap perangkat lunak yang akan dibuat, mendefinisikan objektif keseluruhan dari software, mengidentifikasikan segala kebutuhan, kemudian dilakukan "perancangan kilat" yang difokuskan pada penyajian aspek yang diperlukan agar pelanggan lebih terbayang dengan apa yang sebenarnya diinginkan (Guritno, 2011). Model Prototipe dapat dilihat pada gambar 2.

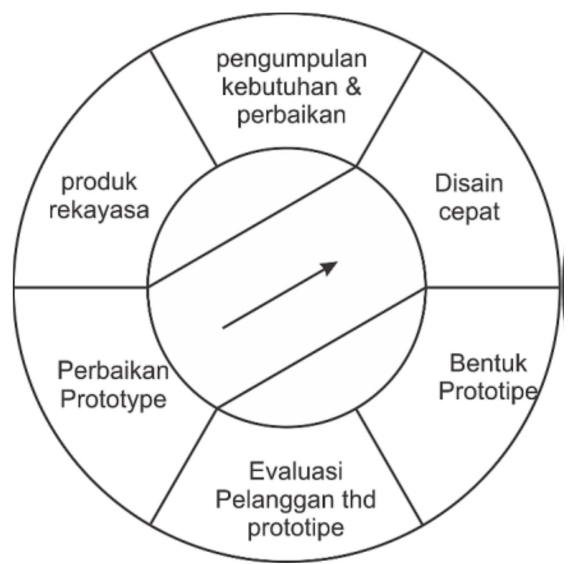

Gambar 2 Model Prototipe

Tahapan-tahapan dalam Prototyping pada penerapan wajan bolic adalah sebagai berikut:

1. Definisi user bersifat umum, user tidak tahu pasti apa yang diinginkan definisi user bersifat tidak rinci, user tidak tahu pasti apa \& bagaimana bentuk.

a. Masukan, dari studi lapangan jarak BTS dengan titik penempatan wajan bolic di desa cibuntu.

b. Proses, mengukur sejauh mana kecocokan desain wajan dan penggunaan provider serta pembuatan wajan bolic.

c. Keluaran, berupa antena wajan bolic dengan diameter $44 \mathrm{~cm}$ dan provider yang paling kuat sinyalnya.

2. Analisis. Dalam tahapan analisis untuk pembuatan wajan bolic selain melakukan pengumpulan data seperti observasi, wawancara, dilakukan juga analisis kebutuhan fungsional dan non fungsional yaitu :

a. Kebutuhan Fungsional

i. Wajan bolic dapat menangkap sinyal dari BTS yang berjarak $\pm 5 \mathrm{~km}$

ii. Kecepatan bandwidth rata-rata $<100 \mathrm{~ms}$ untuk mendapatkan sinyal stabil dan memanggil beberapa domain.

iii. Penggunaan provider berdasarkan sinyal yang didapat pada kampung kambing, yaitu sebanyak 4 provider diantaranya simpati (telkomsel), three, im3 (indosat) dan xl.

b. Non Fungsional

i. Hardware yang digunakan yaitu wajan dengan diameter $44 \mathrm{~cm}$ dengan 2 bahan wajan yaitu bahan aluminium murni dan aluminium campuran atau babet

ii. Modem 3G/4G untuk kemampuan pengiriman data 
3. Pengembang perangkat Wajan Bolic, membuat alat yang berupa wajan, dengan terintegrasi secara langsung dengan modem wireless dan Access point untuk disebarkan pada daerah sekitarnya dengan jarak \pm 10 meter

\section{HASIL DAN PEMBAHASAN}

\section{Perhitungan Untuk Pembuatan Wajan Bolic}

Berdasarkan rumus perhitungan untuk membuat wajan bolic dapat dilihat pada gambar 2 sebagai berikut.

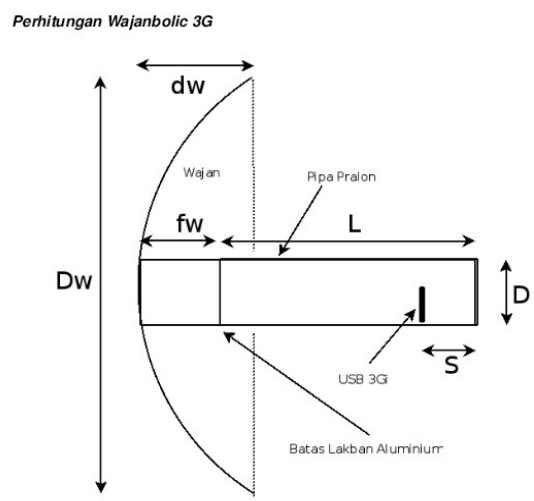

Gambar 3 Komponen Perhitungan Wajan Bolic

Peralatan wajan yang diimplementasikan sebagai berikut :
1. $\mathrm{dw}=11 \mathrm{~cm}$
2. $\mathrm{Dw}=44 \mathrm{~cm}$
3. $\mathrm{fw}=\left(\mathrm{Dw}^{2} /(16 \mathrm{x} \mathrm{dw})\right)=(44 \times 44) /(16 \times 11)=1.936 / 176=11 \mathrm{~cm}$

\section{Implementasi Wajan Bolic Pada Desa Wisata Cibuntu}

Bahan wajan yang digunakan akan dibuatkan sedemikian rupa kedalam bentuk wajan dengan ukuran diameter $44 \mathrm{~cm}$ dan akan dipasang pada balai desa untuk diuji daya penerimaan sinyalnya. Berikut penampakan wajan bolic sesuai dengan bahan yang dipilih:

1. Wajan bolic berbahan aluminium murni 


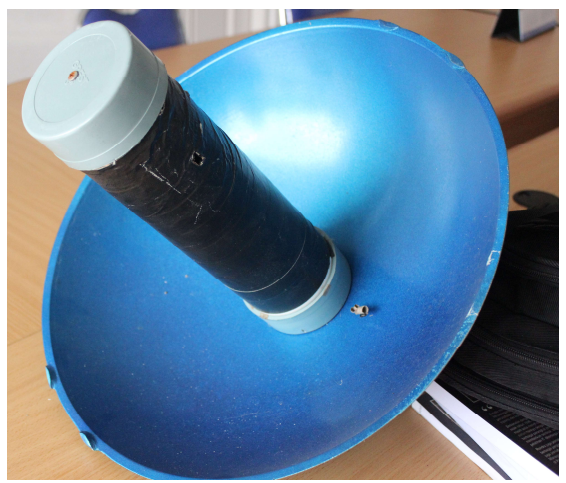

Gambar 4 Wajan Bolic Berbahan Aluminium Campuran atau Babet

2. Wajan bolic berbahan aluminium campuran atau babet

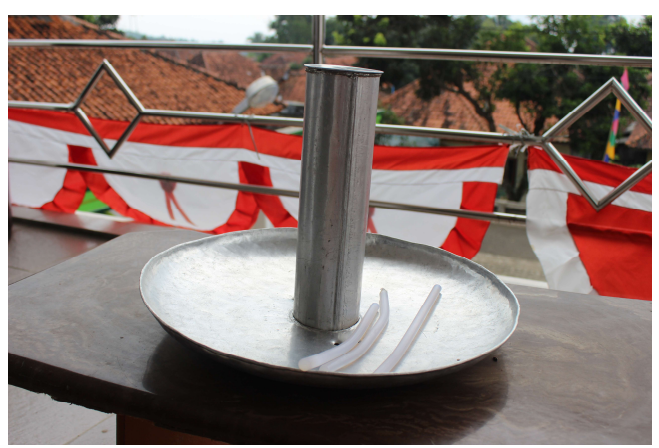

Gambar 5 Wajan Bolic Berbahan Aluminium Murni

Setelah kedua bahan wajan itu dibentuk menjadi bentuk wajan maka kedua wajan tersebut akan dipasang pada lantai 2 kantor balai desa yang dapat dilihat pada gambar dibawah ini.

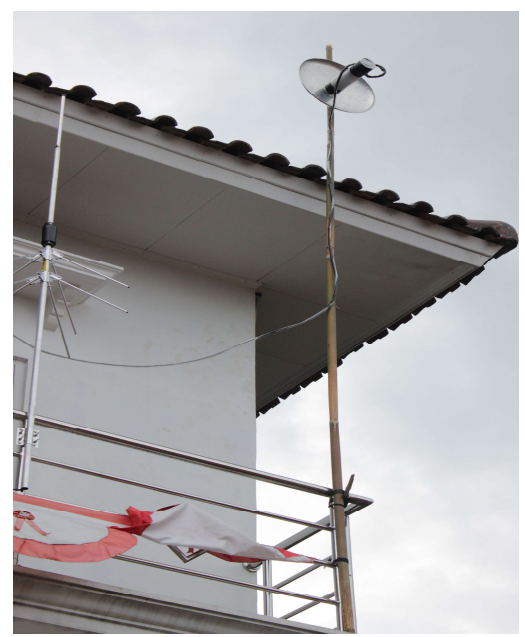

Gambar 6 Implementasi Wajan Bolic Pada Lantai 2 Balai Desa Cibuntu 


\section{Arsitektur Wajan Bolic Pada Desa Cibuntu}

Rancangan arsitektur wajan bolic pada Desa Cibuntu sama seperti penelitian terdahulu yaitu dengan mengambil secara langsung pada BTS terdekat, yang memiliki sinyal terkuat dari provider, penentuan provider yang kuat memudahkan pada saat implementasi wajan bolic, karena penggunaan modem wireless secara langsung mengakses BTS terdekat ditunjukkan pada gambar 6 sebagai berikut:

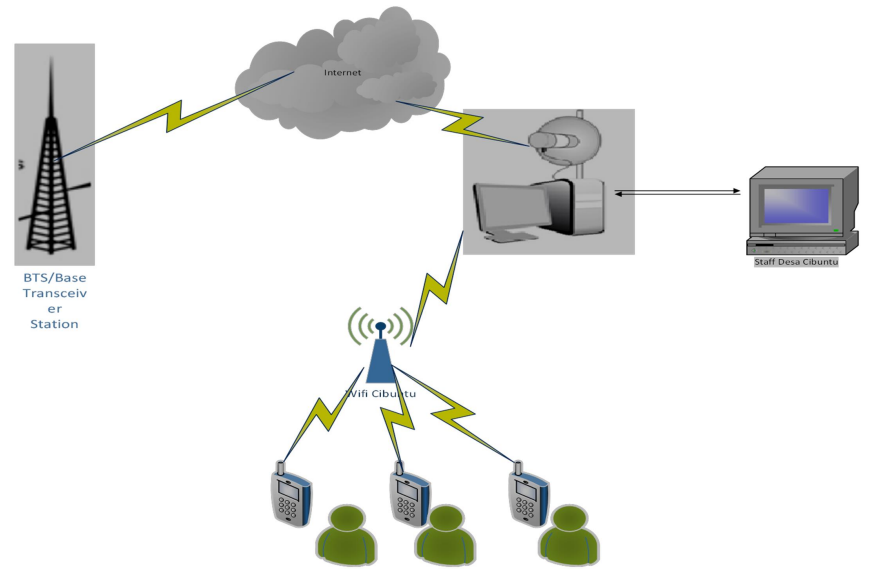

Gambar 7 Usulan Rancangan Arsitektur Wajan Bolic Pada Desa Cibuntu

\section{Hasil Analisis Pemakaian Bahan Wajan Bolic dan Provider Telekomunikasi Pada Desa Cibuntu}

Analisis pemakaian bahan wajan dan provider yang digunakan dilakukan untuk mempermudah dalam perancangan dan membangun wajan bolic yang lebih baik sehingga wajan bolic tersebut dapat bermanfaat bagi pengurus dan masyarakat desa. Hasil analisis perbandingan bahan wajan dan provider telekomunikasi yang dilakukan dibagi berdasarkan 2 bahan yaitu aluminium murni dan aluminium campuran (babet). Analisis dilakukan dengan melakukan pengiriman packet (ping) ke target link yang ditentukan dan diambil 5 sampel ping time terkecil sebagai acuan dalam pengambilan kesimpulan terbaik. Analisis juga dilakukan dengan hanya menggunakan 2 link target yaitu google.com dan kompas.com dengan alasan bahwa google.com merupakan link target yang memiliki content website yang ringan sedangkan kompas.com merupakan link target yang memiliki content website yang berat dikarenakan informasi yang terdapat didalamnya tidak hanya berupa tulisan tetapi dapat berisi gambar, animasi maupun video.

\section{Aluminium Murni}

Untuk mempermudah dalam menganalisa bahan wajan mana yang terbaik untuk digunakan dalam pembuatan wajan bolic maka aluminium murni yang pertama untuk dijadikan perbandingan dengan pemakaian perbandingan provider telekomunikasi yang dapat dilihat pada tabel 1. Untuk provider xl ternyata tidak mendapatkan sinyal yang stabil sehingga tidak dapat terkoneksi dengan benar sedangkan untuk provider three (3) juga tidak mendapatkan jangkauan sinyal. Oleh sebab itu pada tabel 1 dan tabel 2 bagian provider $\mathrm{xl}$ dan three tidak terisi dengan sample ping time. 
Tabel 1 Tabel Perbandingan wajan berbahan aluminium murni dengan beberapa provider telekomunikasi

\begin{tabular}{|c|c|c|c|c|c|c|c|c|c|c|}
\hline \multirow[b]{2}{*}{ Provider } & \multirow[b]{2}{*}{ Target link } & \multirow{2}{*}{$\begin{array}{c}\text { Percobaan } \\
\text { ke- }\end{array}$} & \multicolumn{5}{|c|}{ Ping time (ms) } & \multirow{2}{*}{$\begin{array}{c}\text { Average } \\
\text { (ms) }\end{array}$} & \multirow{2}{*}{$\begin{array}{l}\text { Waktu } \\
\text { sample }\end{array}$} & \multirow{2}{*}{$\begin{array}{c}\text { Tingg } \\
\text { wajan } \\
(\mathrm{m})\end{array}$} \\
\hline & & & 1 & 2 & 3 & 4 & 5 & & & \\
\hline \multirow{9}{*}{ Simpati } & \multirow{6}{*}{ Google.com } & 1 & 112 & 113 & 115 & 149 & 211 & 140 & 14.19 & 12 \\
\hline & & 2 & 119 & 124 & 131 & 139 & 140 & 130.6 & 14.25 & 12 \\
\hline & & 3 & 107 & 116 & 118 & 119 & 120 & 116 & 14.27 & 12 \\
\hline & & 4 & 90 & 91 & 93 & 97 & 99 & 94 & 14.30 & 12 \\
\hline & & 5 & 77 & 78 & 79 & 80 & 81 & 79 & 14.31 & 12 \\
\hline & & 6 & 95 & 98 & 99 & 100 & 102 & 98.8 & 14.32 & 12 \\
\hline & \multirow{3}{*}{ Kompas.com } & 1 & 104 & 107 & 111 & 116 & 124 & 112.4 & 15.01 & 12 \\
\hline & & 2 & 81 & 86 & 88 & 89 & 90 & 86.8 & 15.02 & 12 \\
\hline & & 3 & 75 & 79 & 80 & 81 & 82 & 79.4 & 15.03 & 12 \\
\hline $\mathrm{xl}$ & Google.com & 1 & - & - & - & - & - & - & 15.50 & 12 \\
\hline Three (3) & Google.com & 1 & - & - & - & - & - & - & 15.38 & 12 \\
\hline \multirow{9}{*}{$\operatorname{Im} 3$} & \multirow{6}{*}{ Google.com } & 1 & 73 & 75 & 77 & 79 & 80 & 76.8 & 15.20 & 8 \\
\hline & & 2 & 109 & 110 & 111 & 113 & 114 & 111.4 & 15.21 & 8 \\
\hline & & 3 & 286 & 293 & 308 & 316 & 319 & 304.4 & 15.22 & 8 \\
\hline & & 4 & 121 & 136 & 139 & 405 & 686 & 297.4 & 15.23 & 8 \\
\hline & & 5 & 246 & 257 & 260 & 274 & 287 & 264.8 & 15.26 & 8 \\
\hline & & 6 & 107 & 108 & 110 & 112 & 113 & 110 & 15.27 & 8 \\
\hline & \multirow{3}{*}{ Kompas.com } & 1 & 78 & 81 & 86 & 87 & 88 & 84 & 15.35 & 8 \\
\hline & & 2 & 78 & 81 & 86 & 87 & 88 & 84 & 15.37 & 8 \\
\hline & & 3 & 318 & 374 & 378 & 537 & 795 & 480.4 & 15.38 & 8 \\
\hline
\end{tabular}

\section{Aluminium campuran}

Setelah bahan aluminium murni yang digunakan dalam perbandingan pemakaian bahan wajan bolic, yang berikutnya adalah bahan aluminium campuran atau babet. Perbandingan bahan aluminium campuran sama dengan perbandingan aluminium murni sebelumnya yaitu bahan babet ini akan di gunakan dengan provider telekomunikasi yang sudah ditentukan. Perbandingan bahan babet dengan provider telekomunikasi dapat dilihat pada tabel 2 .

Tabel 2 Tabel Perbandingan wajan berbahan aluminium campuran (babet) dengan beberapa provider telekomunikasi.

\begin{tabular}{|c|c|c|c|c|c|c|c|c|c|c|}
\hline \multirow[b]{2}{*}{ Provider } & \multirow[b]{2}{*}{ Target link } & \multirow{2}{*}{$\begin{array}{l}\text { Percobaan } \\
\text { ke- }\end{array}$} & \multicolumn{5}{|c|}{ Ping time (ms) } & \multirow{2}{*}{$\begin{array}{c}\text { Average } \\
\text { (ms) }\end{array}$} & \multirow{2}{*}{$\begin{array}{l}\text { Waktu } \\
\text { sample }\end{array}$} & \multirow{2}{*}{$\begin{array}{c}\text { Tinggi } \\
\text { wajan } \\
(\mathrm{m})\end{array}$} \\
\hline & & & 1 & 2 & 3 & 4 & 5 & & & \\
\hline \multirow{2}{*}{ Simpati } & Google.com & 1 & 92 & 115 & 180 & 192 & 199 & 155.6 & 15.40 & 12 \\
\hline & Kompas.com & 1 & 73 & 74 & 76 & 77 & 81 & 76.2 & 15.42 & 12 \\
\hline $\mathrm{xl}$ & Google.com & 1 & - & - & - & - & - & - & 15.45 & 12 \\
\hline Three (3) & Google.com & 1 & - & - & - & - & - & - & 15.48 & 12 \\
\hline \multirow{2}{*}{$\operatorname{Im} 3$} & Google.com & 1 & 222 & 223 & 232 & 244 & 246 & 230.25 & 15.50 & 8 \\
\hline & Kompas.com & 1 & 266 & 267 & 270 & 272 & 284 & 271.8 & 15.52 & 8 \\
\hline
\end{tabular}

\section{Perbandingan Bahan Wajan Bolic}

Setelah menguji penggunaan provider telekomunikasi pada 2 bahan wajan bolic maka peneliti membandingkan 2 bahan wajan tersebut terhadap daya penerimaan sinyal provider yang dimana provider yang diteliti diringkas menjadi 2 provider yaitu simpati dan im3. Hasil perbandingan dapat dilihat pada tabel 3 . 
Tabel 3 Tabel Perbandingan wajan berbahan aluminium murni dan aluminium campuran dengan beberapa provider telekomunikasi.

\begin{tabular}{cccc}
\hline Bahan wajan & Provider & $\begin{array}{c}\text { Rataan } \\
\text { (ping time provider) } \\
(\mathrm{ms})\end{array}$ & $\begin{array}{c}\text { Rataan total } \\
\text { (ping time provider) } \\
(\mathrm{ms})\end{array}$ \\
\hline \multirow{2}{*}{\begin{tabular}{c} 
Aluminium murni \\
\cline { 2 - 3 }
\end{tabular}} & Simpati & 140.11 & 152.79 \\
\hline $\begin{array}{c}\text { Aluminium campuran } \\
\text { (babet) }\end{array}$ & Im3 & 201.47 & \multirow{2}{*}{183.46} \\
\cline { 2 - 3 } & Simpati & 115.90 & 251.03 \\
\hline
\end{tabular}

\section{Perbandingan Provider Telekomunikasi}

Dari analisis bahan wajan maka yang berikutnya adalah merangkum analisis penggunaan provider telekomunikasi yang digunakan. Hasil analisis dilakukan dengan mengambil ping time yang kecil pada 2 provider yang sudah diringkas dari 4 provider yang dibandingkan dikarenakan 2 provider telekomunikasi lainnya yakni three (3) dan xl yang dimana saat penelitian ini dilakukan tidak mendapat respon sinyal yang baik. Tabel hasil perbandingan 2 provider yakni simpati dan im3 dapat dilihat pada tabel 4.

Tabel 4 Tabel Perbandingan beberapa provider telekomunikasi yang digunakan pada penelitian yang akan dijadikan sebagai sumber telekomunikasi dalam dunia maya.

\begin{tabular}{cc}
\hline Provider & Ping time $(\mathrm{ms})$ \\
\hline Simpati & 110.00 \\
\hline Im3 & 226.25 \\
\hline XL & - \\
\hline Three & - \\
\hline
\end{tabular}

\section{KESIMPULAN DAN SARAN}

Kesimpulan yang didapat dari penelitian ini adalah aluminium murni merupakan bahan yang paling baik dalam hal daya penerimaan sinyal di desa Cibuntu jika dibandingkan dengan bahan aluminium campuran atau babet dan Simpati merupakan provider yang kuat sinyalnya paling stabil diantara provider yang diujikan dengan rata-rata ping time $<100 \mathrm{~ms}$ dan ukuran diameter dari wajan bolic yang diujikan sebesar $44 \mathrm{~cm}$.

\section{Ucapan Terima Kasih (Acknowledgement)}

Terima kasih peneliti sampaikan kepada Universitas Bunda Mulia yang telah mendukung sepenuhnya peneliti beserta anggota peneliti lainnya dalam melakukan penelitian di desa Cibuntu.

\section{REFERENSI}

Adiyanto, Molin 2008, Pembuatan Antena Wajanbolic, Teknologi Informasi Institut Teknologi Sepuluh Nopember. 
Guritno, S., Sudaryono, Rahardja, U., 2011. Theory and Application of IT Research: Metodologi Penelitian Teknologi Informasi, Andi Offset, Yogyakarta.

Hakim, Lukman. Agung, Halim. 2016. Penerapan Wajan Bolic Sebagai Penguat Sinyal Seluler Pada Daerah Blank Spot di Desa Wisata Cibuntu, Laporan Penelitian, Universitas Bunda Mulia, Jakarta (Tidak dipublikasikan, dapat diakses di perpustakaan Universitas Bunda Mulia.

Hadiwijoyo, Suryo Sakti. 2012. Perencanaan Pariwisata Perdesaan Berbasis Masyarakat (Sebuah Pendekatan Konsep). Yogyakarta: Graha Ilmu.

Huda, Bayu Nur. 2014, Pembuatan Dan Analisis Perbandingan Kinerja Wajan Bolic Dan Antena Kaleng Dalam Menangkap Sinyal Wifi, Universitas Muhammadiyah Surakarta, Surakarta.

Muslim, Much Aziz. 2008, Pemanfaatan Wajan untuk Antena Wifi, Jurnal Teknologi Informasi DINAMIK Volume XIII, No.2, Juli 2008, ISSN: 0854-9524, Universitas Stikubank Semarang.

Rahman, Widita Prasetia. 2011, Perancangan dan Realisasi Penguat Pada Wifi, Teknik Elektro Institut Teknologi Nasional Bandung.

Wikipedia, 2012, Wajanbolic e-goen. http://opensource.telkomspeedy.com/wiki/index.php/Wajanbolic_e-goen. (Diakses 7 Maret 2017)

Yasin, Verdy. 2012, Rekayasa Perangkat Lunak Berorientasi Objek, Mitra Wacana Media, Jakarta.

Yurandi, Nugraha. Jambola, Lucia. Darlis, Arsyad R., 2013. Perancangan dan Implementasi Reflector Antena Wifi dengan frekuensi 2.4 GHz, Jurnal Online Reka Elkomika Volume I, No.3, Februari 2013, ISSN: 2337 - 439X. Institut Teknologi Nasional. 